\title{
SEISMIC HAZARDS AND WATER SUPPLY PERFORMANCE
}

\author{
A Thesis \\ Presented to the Faculty of the Graduate School \\ of Cornell University \\ In Partial Fulfillment of the Requirements for the Degree of \\ Master of Science
}

by

Natalia Romero

August 2009 
(C) 2009 Natalia Romero 


\begin{abstract}
This thesis describes seismic hazards, including fault rupture, liquefaction, landslides, and site amplification, using Los Angeles as a case study. Water supply simulation results are presented for a 7.8 MW earthquake on the San Andreas Fault. Severe water losses are shown after $24 \mathrm{hrs}$, with nearly 2,700 locations of pipeline damage and a $66 \%$ decrease in normal water service. The water supply system was modeled with and without reservoirs that have been removed from service to meet water quality standards. The results show that opening the disconnected reservoirs immediately after a serious earthquake is an effective strategy for emergency response.
\end{abstract}




\section{BIOGRAPHICAL SKETCH}

Natalia was born and raised in Cali, Colombia. After graduating from Liceo Benalcazar, she took six months of English as a Second Language courses at Algonquin College, Nepean, Canada, and six months of French as a Second Language courses at University of The West, Angers, France. In July 2001 she started Law at Javeriana University, Bogota, Colombia, and in August 2002 she transferred to University of Los Andes, Bogota, Colombia, where she graduated with a Bachelor of Science in Civil Engineering and Minor in Law. Natalia worked for a year at University of Los Andes, Center in Water Supply Systems and Sewers, as a Research Engineer in the "Condition Assessment and Damage Management of the Water Supply System of Bucaramanga". Natalia moved to Ithaca in August 2007 to pursue her master and doctoral degrees in the School of Civil and Environmental Engineering at Cornell. 


\section{ACKNOWLEDGMENTS}

First, I must thank the chair of my Special Committee, Professor O'Rourke for giving me the opportunity to be part of the LADWP project and for sharing his knowledge with me. Professor O'Rourke's patience and dedication have truly enriched my experienced at Cornell. My deepest gratitude to Professor Linda K. Nozick, her support, dedication and encouragement have helped to sustain me throughout these first years at Cornell.

I was fortunate to meet and work with Amanda L. Bonneau during her last three months as a graduate student at Cornell. I thank her for finding some time, even after she had graduated, to answer my questions and share her knowledge with me. This work would not have been possible without contributions from the Los Angeles Department of Water and Power (LADWP). Thanks go to Craig Davis, Jianping Hu, and Victor Vargas for their time and contribution to this work. The assistance of Dr. Ken Hudnut of the California Institute of Technology is also deeply appreciated. 


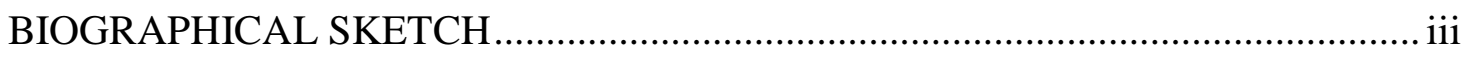

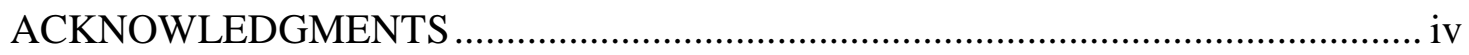

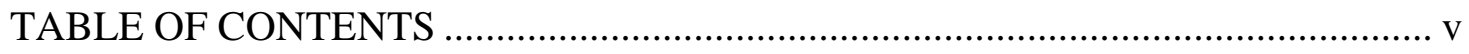

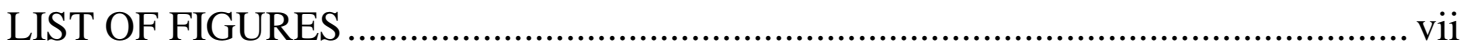

$\begin{array}{lll}\text { CHAPTER } 1 \text { INTRODUCTION } & 1\end{array}$

$\begin{array}{lll}\text { CHAPTER } 2 & \text { DECISION SUPPORT SYSTEM }\end{array}$

$\begin{array}{lll}\text { CHAPTER } 3 & \text { EARTHQUAKE STRONG MOTION }\end{array}$

CHAPTER 4 EARTHQUAKE-INDUCED PERMANENT GROUND

$\begin{array}{lr}\text { DEFORMATION } & 8\end{array}$

CHAPTER 5 NORTHRIDGE EARTHQUAKE PIPELINE

PERFORMANCE

$\begin{array}{lll}\text { CHAPTER } 6 & \text { LA CIENEGA } & 14\end{array}$

CHAPTER 7 MODELING PIPELINE RESPONSE FROM TRANSIENT

GROUND DEFORMATION 21 
CHAPTER 8 PIPELINE DAMAGE FROM PERMANENT GROUND

DEFORMATION 22

CHAPTER 9 SHAKEOUT SCENARIO PIPELINE DAMAGE AND

SYSTEM SERVICEABILITY 24

CHAPTER 10 WATER SERVICE AREAS SERVICEABILITY 29

$\begin{array}{lll}\text { CHAPTER } 11 & \text { EMERGENCY USE OF RESERVOIRS }\end{array}$

$\begin{array}{lll}\text { CHAPTER } 12 & \text { CONCLUSIONS } & 37\end{array}$

REFERENCES 


\section{LIST OF FIGURES}

Figure Page

No. No.

1 (a) Location of San Andreas Fault and LADWP system, (b) PGA 6 contours, (c) PGV contours and SAF.

2 Areas of PGD effects in Los Angeles 9

3 Pipeline repair rate contours for the 1994 Northridge earthquake 13

4 Map of La Cienega area 15

5 Cross-section A-B showing soils, groundwater table, and 17 liquefiable sands

6 Flow charts for estimating pipeline damage at PGD locations

$7 \quad$ Bar chart of pipeline repairs caused by ShakeOut scenario earthquake

$8 \quad$ Histogram of system serviceability immediately following and $24 \quad 26$ hours after the ShakeOut scenario earthquake

9 Schematic of Hose and Pumper System for Hydraulic Network Modeling of Fireboat Firefighter Flows to WTC Site

10 Location of LADWP water service areas

11 Bar chart of LADWP water service areas serviceability index (SI) 30 


\section{Figure}

12 Locations of LA, Encino, Lower Stone Canyon and Hollywood reservoirs

13 SSI at 24 hours for ShakeOut scenario earthquake, using summer demands with Encino, Lower Stone Canyon and Hollywood reservoirs open and closed.

14 SI for WS, CC, HP, and MW water service areas at 24 hours after the ShakeOut scenario earthquake, using summer demands with Encino, Lower Stone Canyon and Hollywood reservoirs open and closed. 


\section{CHAPTER 1}

\section{INTRODUCTION}

Seismic hazards and water supply performance were investigated for a scenario 7.8 MW earthquake in Los Angeles, CA. The study was conducted in coordination with the Los Angeles Department of Water and Power (LADWP) as part of the Great Southern California ShakeOut, which was the largest earthquake preparedness drill in US history, with an estimated 5.47 million people participating [Cox and Pierce, 2008]. Under the guidance of the US Geological Survey (USGS) a multi-disciplinary team of experts developed the ShakeOut scenario to examine the regional effects of a major earthquake in southern California using physics-based computer simulations of fault rupture and earthquake ground motions [USGS, 2008a]. The ShakeOut Scenario earthquake is a 7.8 MW earthquake on the southernmost $300 \mathrm{~km}$ of the San Andreas Fault (SAF), which ruptures from the Salton Sea northwest to Lake Hughes, passing east of Los Angeles. The ShakeOut scenario strong ground motion model includes attenuation, site effects, directivity, and radiation patterns at different locations in southern California. The losses resulting from the ShakeOut Scenario earthquake are estimated at 1,800 deaths and \$213 billion [USGS, 2008a].

The seismic performance of the LADWP water distribution system was simulated with special software and a hydraulic network model developed through collaboration among Cornell University researchers, Multidisciplinary Center for Earthquake Engineering Research (MCEER), and LADWP. The modeling accounts for the response of heavily damaged hydraulic networks through the elimination of pipelines and associated facilities that cannot sustain reliable flow and the analysis of the remaining parts of the system that are still functional. 
This paper describes the decision support system that was developed in partnership with LADWP to model the response of its water supply to earthquake effects. It describes the ShakeOut strong ground motions and locations of permanent ground deformation resulting from fault rupture, liquefaction, landslides, and ground lurching caused by failure in soft clay deposits.. The models for simulating pipeline performance under transient and permanent ground deformation are discussed, and the results of the ShakeOut earthquake/water supply simulations are summarized with respect to pipeline repairs and serviceability. 


\section{CHAPTER 2}

\section{DECISION SUPPORT SYSTEM}

A decision support system was developed by using the LADWP water supply as a test bed. The system is intended to plan operations, emergency response, and new system facilities and configurations to optimize water supply performance during and after earthquakes [O'Rourke et al, 2008]. The system is generic, and the architecture of its computer programs is adaptable to any water supply. The system works in conjunction with an easily accessible hydraulic network model, EPANET, which is available on-

line from the U.S. Environmental Protection Agency [EPA, 2007] as well as a special program for damaged network flow modeling, known as Graphical Iterative Response Analysis for Flow Following Earthquakes (GIRAFFE). Detailed information about the development and evaluation of GIRAFFE is provided by Bonneau [2008], Wang [2006], Shi [2006], Shi et al. [2006], and Wang and O’Rourke [2007].

As described by O'Rourke, et al. [2008], the hydraulic network model utilized by the decision support system accounts for all 11,691 km of water trunk and distribution pipelines and related facilities (e.g., tanks, reservoirs, pressure regulation stations, etc.) in the LADWP system. The system also accounts for the aggregated seismic hazard in Los Angeles through an ensemble of 59 scenario earthquakes. The 59 scenario earthquakes provide a library of seismic scenarios, from which engineers can select specific scenarios or combinations of scenarios to assess system performance. The decision support system works with risk and reliability assessment tools to provide metrics of system performance. The computer simulations account for the interaction of the water and electric power supplies, and model output can be used to evaluate the regional economic and community impacts of water losses. All system input and 
output can be visualized through GIS with advanced query logic and web-based features. The simulations are dynamic in time, and can account for loss of service as tanks and local reservoirs lose water over time through leaks and breaks in pipelines. 


\section{CHAPTER 3}

\section{EARTHQUAKE STRONG MOTION}

The ShakeOut scenario earthquake is a physics-based simulation of strong motion that accounts for site effects, directivity, and radiation patterns. The simulation includes a kinematic rupture description and a velocity model developed from the characteristics of southern California bedrock. The strongest ground shaking in the City of Los Angeles is locally in the range of $200 \mathrm{~cm} / \mathrm{sec}$ and lasts for about 20-45 sec [USGS, 2008a].

Figure 1 (a) shows a regional map of the Los Angeles area in which the LADWP water distribution system is located relative to the SAF. The central part of the LADWP system, centered on downtown Los Angeles, is located approximately $55 \mathrm{~km}$ from the SAF. The strong ground motion in the area can be described by peak ground velocity (PGV) and peak ground acceleration (PGA). The shape files for the areal distribution of PGA and PGV of both maps are available at the USGS WebSite [USGS, 2008b]. According to the model, the strong shaking in the Los Angeles area starts $70 \mathrm{sec}$. after initiation of the fault rupture and lasts for a total of $55 \mathrm{sec}$. Figure 1 (b) presents the spatial distribution of PGA generated by the earthquake. The San Fernando Valley and the southern part of the service area are the locations of maximum PGA (approximately $0.3 \mathrm{~g}$ ) affecting the LADWP system. Figure 1 (c) presents the SAF rupture and distribution of PGV. The locations of maximum PGV correspond to deep sediment basins, which amplify the incoming ground waves to produce locally high PGV. There are two main locations of wave amplification in the northern part of the San Fernando Valley and an area southeast of the Civic Center, where PGVs approach $200 \mathrm{~cm} / \mathrm{sec}$. 




Figure 1. (a) Location of San Andreas Fault and LADWP system, (b) PGA contours, (c) PGV contours and SAF.

Pipeline damage caused by transient ground deformation (TGD), or seismic waves, is estimated by means of regressions developed from previous earthquake records. Those regressions correlate pipeline repair rates (RR), defined as the number of repairs per km, with PGV. Regressions developed by Jeon and O'Rourke [2005] and Wang [2006] for water distribution and trunk lines, respectively, are used.

Demands from the distribution pipelines are modeled as flow requirements at 1,052 demand nodes throughout the system. Distribution pipeline behavior is accounted for 
by fragility curves that correlate distribution system demands with RRs. In addition to modeling pipeline damage, it is important to account for the vulnerability of other facilities in the system. For example, tank damage is modeled by fragility curves developed for different types of tanks used by LADWP. Fragility curves proposed by O'Rourke and So [2000] for steel tanks and fragility curves used in HAZUS [FEMA, 2006] for concrete tanks are incorporated in the simulations. 


\section{CHAPTER 4}

\section{EARTHQUAKE-INDUCED PERMANENT GROUND DEFORMATION}

In addition to seismic ground waves, earthquakes trigger permanent ground deformation (PGD) primarily in the form of fault rupture, liquefaction-induced ground movement, and landslides. The ShakeOut SAF rupture at its intersection with the Los Angeles Aqueducts (LAAs) is $3.3 \mathrm{~m}$ in length [USGS, 2008a]. Because such a large fault rupture will disrupt the aqueducts, the water distribution network response was simulated by removing the LAAs from the LADWP hydraulic network model. The City of Los Angeles gets $85 \%$ of its water from the LAAs, California Aqueduct (CA), and Colorado River Aqueduct (CRA), and 15\% from groundwater sources. The CA and CRA are also severely damaged by fault rupture and strong ground shaking [Davis, 2009a,b].

The ShakeOut scenario provides predictions of PGD associated with soil liquefaction in the form of settlement caused by post-liquefaction consolidation and lateral spreading. Post-liquefaction consolidation is caused by loss of volume in the soil as porewater pressures dissipate after liquefaction. As described by USGS [2008a], locations of potentially liquefiable soils were identified in the ShakeOut modeling, and the method proposed by Tokimatsu and Seed [1987] was used in conjunction with estimated PGAs to predict soil settlements. Horizontal ground movement associated with lateral spreading was estimated according to the procedures used in HAZUS [FEMA, 2003], which are based on the Liquefaction Severity Index proposed by Youd and Perkins [1986]. 
As described by USGS [2008a], mapped geologic units were categorized into landslide susceptibility classes according to the methods developed by Wilson and Keefer [1985]. Similar to the approach taken for liquefaction, landslide PGDs were estimated by following the procedures in HAZUS [FEMA, 2003] whereby the ratio of predicted to critical acceleration for various landslide susceptibility classes are used in combination with analytical results summarized by Makdisi and Seed [1978] to estimate earthquake-induced displacments.

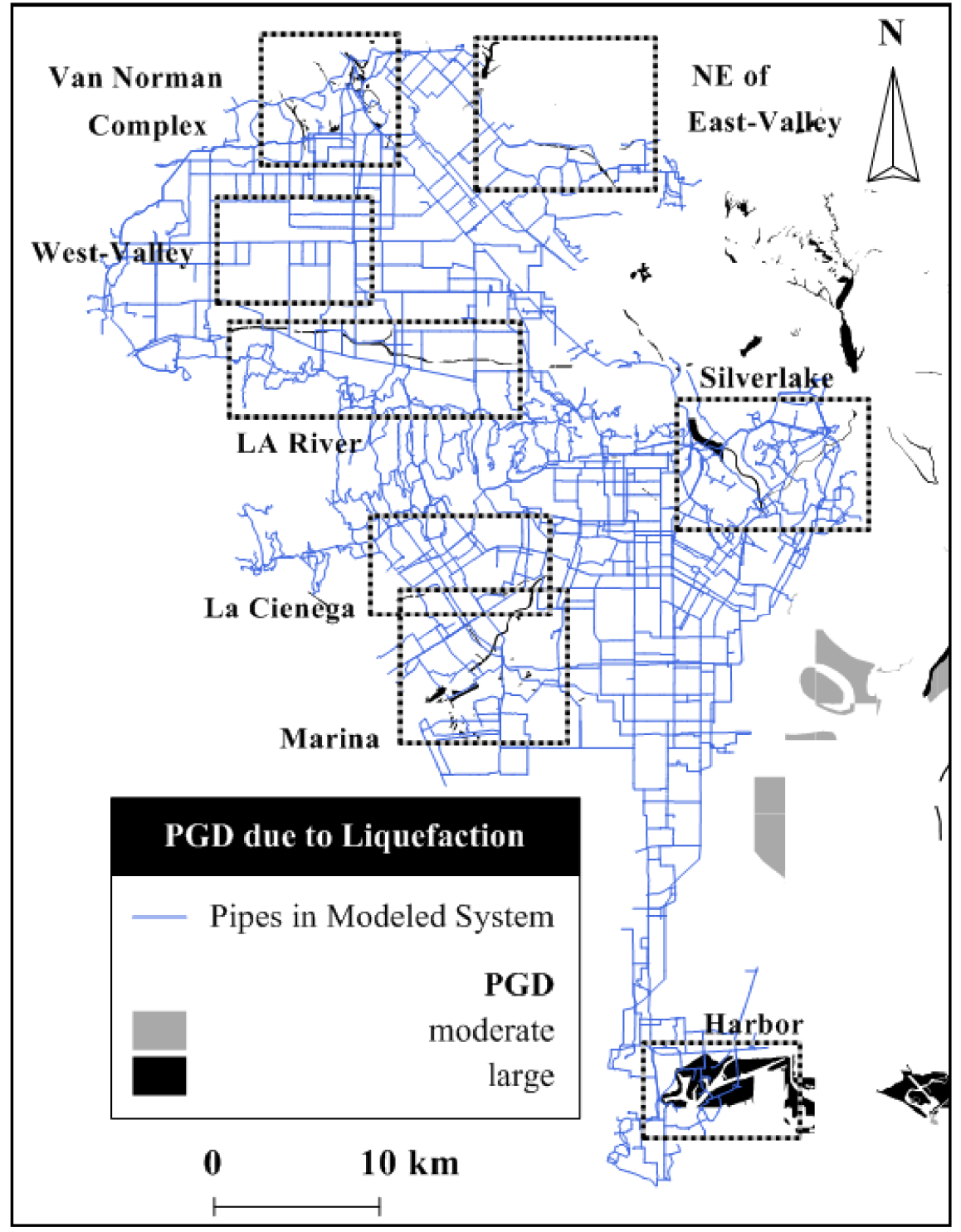

Figure 2. Areas of PGD effects in Los Angeles 
Within the LADWP system, there are only a few zones of high landslide susceptibility indentified in the ShakeOut Scenario [USGS, 2008a], with low impact on water supply performance. The predominant PGD hazards affecting the LADWP water distribution network are liquefaction and ground lurching triggered by failure in soft clay deposits.. Figure 2 provides a map of the LADWP system in which areas of liquefaction hazards and estimates of PGD provided with the ShakeOut Scenario are identified. Also identified is the La Cienega area, which is discussed in detail in the section of this paper entitled La Cienega. As discussed in the next section, water pipeline damage during the 1994 Northridge earthquake was caused by ground lurching in the West Valley area. 


\section{CHAPTER 5}

\section{NORTHRIDGE EARTHQUAKE PIPELINE PERFORMANCE}

To help with the evaluation of pipeline performance, pipeline damage during the 1994 Northridge earthquake was used to identify locations in the LADWP system that are vulnerable to earthquake effects because of underlying geotechnical conditions. The 1994 Northridge earthquake caused the most extensive damage to a US water supply system since the 1906 San Francisco earthquake. LADWP and the Metropolitan Water District of Southern California (MWD) trunk lines (nominal pipe diameter $\square 600$ $\mathrm{mm}$ ) were damaged at 74 locations within the LADWP service area, and the LADWP distribution pipeline (nominal pipe diameter $<600 \mathrm{~mm}$ ) system was repaired at 1,013 locations [Jeon and O’Rourke, 2005].

Information on water pipeline repairs after the Northridge earthquake, including location, pipe diameter and composition were collected and geocoded [Jeon and O’Rourke, 2005; O’Rourke and Toprak, 1997]. In addition, approximately 11,000 km of distribution mains and 1,000 km of trunk lines operated throughout the City of Los Angeles were digitized. This information was incorporated into a GIS database using ArcInfo software, where it was combined with corrected strong motion records [Jeon and O'Rourke, 2005]. The records from 241 Northridge earthquake strong motion instruments were examined, and the data from 164 corrected records were selected for detailed analyses.

Cast iron pipelines, comprised approximately $75 \%$ of the LADWP distribution network at the time of the Northridge earthquake. Hence, there was sufficiently broad coverage of cast iron pipelines so that their RRs represent seismic response throughout 
the entire system. Moreover, cast iron is a brittle material, sensitive to seismic effects, and thus a suitable choice for evaluating the spatial variation of the earthquake's influence.

Figure 3 presents a map of cast iron distribution pipeline repair locations and repair rate $(\mathrm{RR})$ contours for pipeline damage. The RR contours were developed by dividing the map into $2 \mathrm{~km} \times 2 \mathrm{~km}$ areas, determining the number of pipeline repairs in each area, and dividing the number of repairs by the length of distribution pipeline in that area. Contours then were drawn from the spatial distribution of RRs, each of which was centered on its tributary area. The $2 \mathrm{~km} \times 2 \mathrm{~km}$ grid was found to provide a good representation of damage patterns for the map scale of the figure [Jeon and O'Rourke, 2005] O’Rourke and Toprak, 1997].

The contour interval of $0.1 \mathrm{RR} / \mathrm{km}$ in Figure 3 is equal to the average cast iron pipeline repair rate for the entire system. Concentrations of contour lines therefore represent areas where damage to the pipelines was above the mean. The scale of the damage and intensity of the seismic effects are proportional to the number of contour intervals in a given area.

Most areas of RR contour concentrations coincide with areas of liquefaction hazards identified in the ShakeOut Scenario (see Figure 2). The liquefaction characterization and PGD predictions in the ShakeOut Scenario were checked and judged to be suitable at all locations except the two zones of RR contour concentrations identified in Figure 3 as the West Valley and La Cienega areas. 


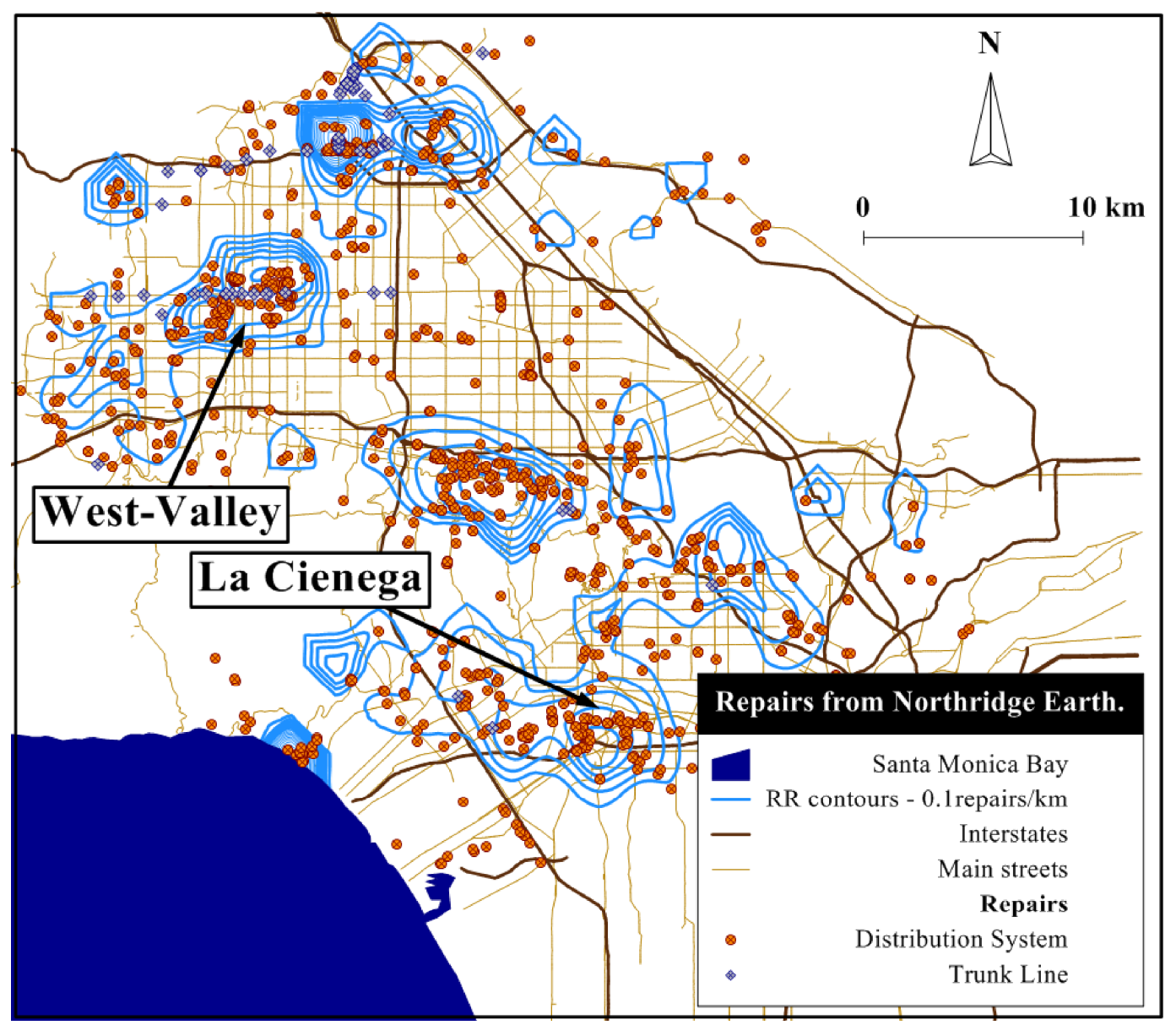

Figure 3. Pipeline repair rate contours for the 1994 Northridge earthquake.

Investigations performed by USGS after the Northridge earthquake disclosed layers of soft, normally consolidated clay in the West Valley area that contributed to lateral movements as high as 300 to $600 \mathrm{~mm}$ [Holzer et al., 1999]. Newmark sliding block analyses [O'Rourke, 1998] show that ground movement of the same magnitude and direction of movement as mapped by USGS were caused by low undrained shear strength of the clay in combination with near source pulses of high acceleration. The principal cause of ground displacement and pipeline damage in the West Valley area therefore is regarded as ground failure and slip in the soft clay deposits. This phenomenon of permanent ground movement in the absence of liquefiable soils is often referred to as lurching. 


\section{CHAPTER 6}

\section{LA CIENEGA}

The La Cienega area, as defined in this study, is shown in Figure 4. The surficial soils are described as younger Quaternary soils, consisting of alternating beds of fine to medium grained sands, silts, and clay, associated either with alluvial fan deposits or with sediments deposited along and adjacent to Ballona Creek and the ancestral course of the Los Angeles River [Mattison and Lloyd, 1998; Lisle, 1998]. Historic high water tables are plotted in this area at $3-7 \mathrm{~m}$ below ground surface, and the soils are identified as susceptible to liquefaction [USGS, 1999 a,b; Mattison and Lloyd, 1998; Lisle, 1998].

This area was the location of serious bridge damage during the Northridge earthquake. Yashinski [1995a and 1995b] described two locations of bridge damage at the two intersections I-10 with La Cienega Blvd. and Faifax Ave. where failure of reinforced concrete columns resulted in collapse at the I-10 overpasses. It was noted in the reconnaissance observations that the bridge failures were consistent with ground motions higher than those recorded by the nearest strong motion instruments. Onedimensional site response analyses were subsequently performed in which earthquake motions recorded $2.3 \mathrm{~km}$ away were used in combination with deep shear wave velocity profiles measured at both the I-10-La Cienega and recorded strong motion sites to estimate surface motion at the I-10 collapse location [Boore, et al., 2003]. The analytical results show ground motions at the I-10-La Cienega site higher than those from the nearest recording by a factor of 1.2 to 1.6. The increased analytical motion was mainly due to softer sediments in the upper $12.5 \mathrm{~m}$ of the soil column. 
The earliest topographic and geologic maps of the area were collected and reviewed, including the 1893-94 [USGS, 1896] and 1926 USGS topographic maps [USGS, 1926; USGS, 1925]. Features from the 1926 topographic map were digitized and combined in Figure 4 with current topographic and street maps as well as the locations of Northridge earthquake pipeline repairs and I-10 bridge damage.

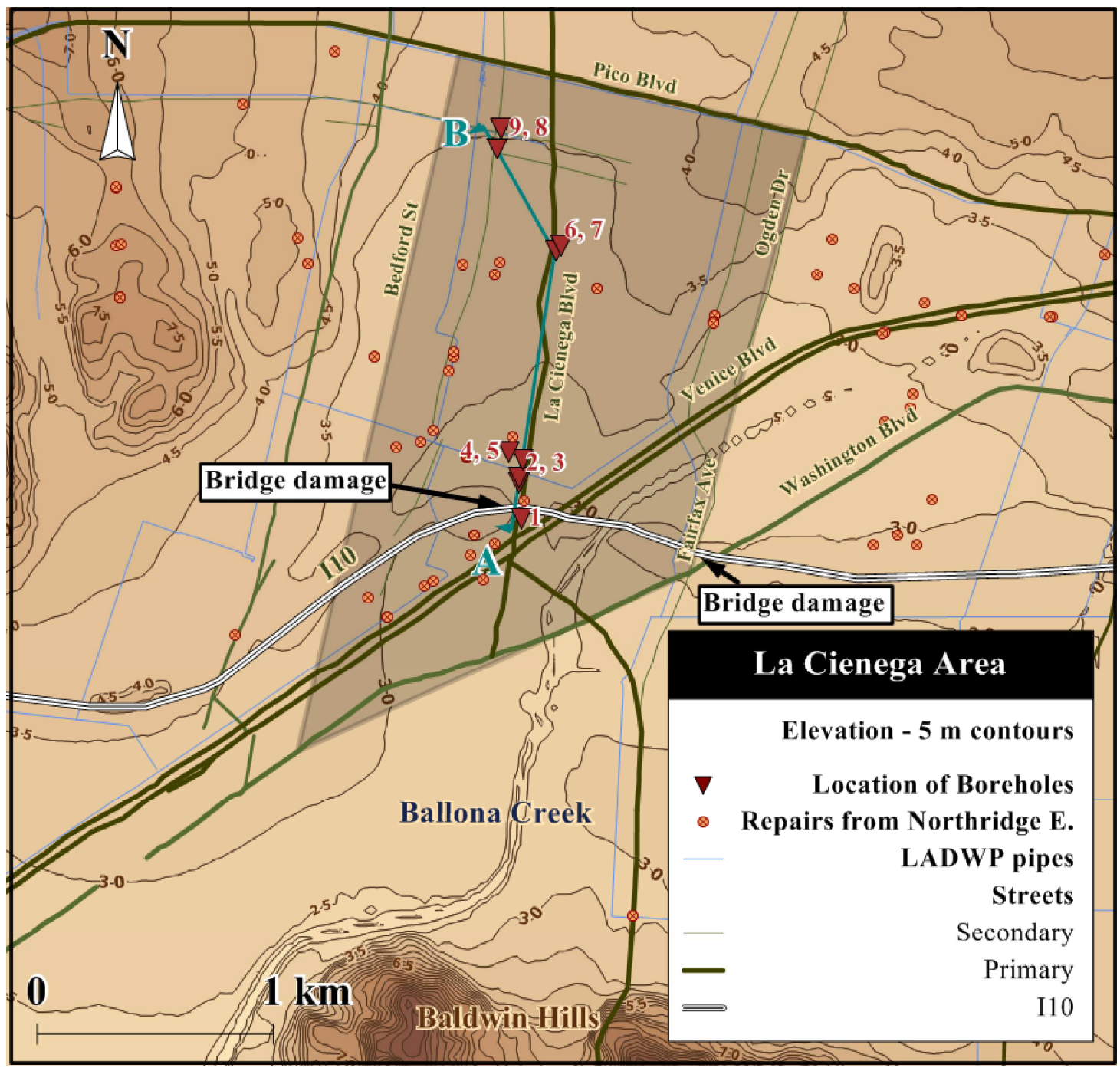

Figure 4. Map of La Cienega area 
The highest levels of pipeline repairs were located in a zone of low elevation near the southern boundary of the alluvial fan deposits south of the Santa Monica Mountains and immediately north of Ballona Creek, which is located along the northern flank of the Baldwin Hills. The zone of highest damage was located just north of the damaged I-10 bridge. It was centered along La Cienega Blvd., which follows the course of an old tributary to Ballona Creek where swamps were identified in the 1926 USGS topographic map [USGS, 1926].

The water distribution pipelines in this zone are 70 - 90 years old, composed mostly of cast iron with lead-caulked joints, with nominal diameters of $150-300 \mathrm{~mm}$ of which $150 \mathrm{~mm}$ is the predominant size. Records at LADWP show that pipeline repairs in this zone since the Northridge earthquake are 2 - 3 times higher than those in adjacent parts of the system. Elevated levels of continued pipeline repair have been observed after previous earthquakes in zones of high seismic disturbance [Isenberg, 1986]. The high post-earthquake repair rates not only show that the pipelines are vulnerable due to their state of repair, but that the high levels of maintenance may provide indirect evidence of locally high seismic hazard.

Borehole data were collected from the LADWP, California State Water Resources Control Board [2009], and the Rosrine project database [Rosrine, 2001]. The borehole locations are shown in Figure 4, and a subsurface cross-section developed from the borehole data is presented in Figure 5. The borehole data were collected from 6 different sites and involve 9 borings, each of which is numbered in Figure 4. Close spacing of numbers indicates sites where data from more than one boring was used. Groundwater levels shown for borings 1, 8, and 9 were the highest water level observed during borehole installation. Borings at the remaining locations 


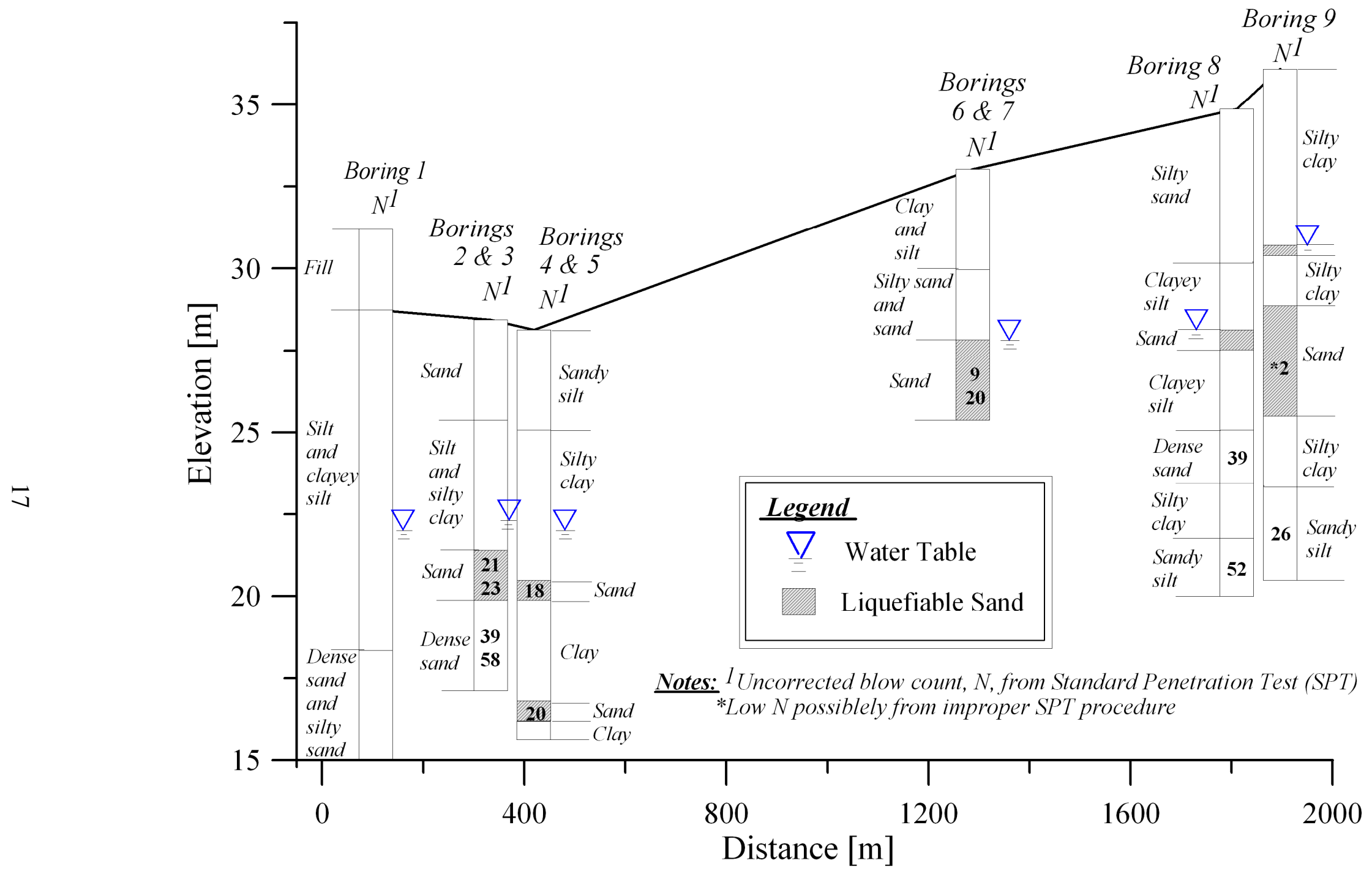

Figure 5. Cross-section A-B showing soils, groundwater table, and liquefiable sands 
were converted to observation wells so that the groundwater here represents a piezometric surface that stabilized several days to months after the boring was made. The groundwater levels are consistently 5 to $8 \mathrm{~m}$ below the ground surface, and liquefiable sand deposits are confined within the upper $12 \mathrm{~m}$ of the soil column.

Standard Penetration Tests (SPTs) were performed in borings 1 through 9 in accordance with ASTM D1586 [ASTM, 1999]. Representative uncorrected blow count values are shown in the figures at depths where sand deposits are assessed as potentially liquefiable.

Potentially liquefiable soils were identified from the procedures summarized by Idriss and Boulanger [2008], whereby safety factor for liquefaction, FSL, is calculated by: $F S_{L}=\left[\frac{C R R_{7.5}}{C S R}\right] * M S F * K_{\sigma}$

in which, CRR7.5 is the cyclic resistance ratio for the $\mathrm{Mw}=6.7$ Northridge earthquake and CSR is the cyclic stress ratio, determined for a peak ground velocity, $\mathrm{amax}=0.36 \mathrm{~g}$ that is consistent with both USGS Shakemap estimates for this location [USGS, 2008c] and estimates from the GIS database described previously for strong motion [Jeon and O'Rourke, 2005]. The MSF is the magnitude scaling factor and $\mathrm{K} \square$ is the overburden correction factor, both of which were determined from SPT data according to the procedures and equations given by Idriss and Boulanger [2008].

All SPT data were corrected according to:

$$
\left(N_{1}\right)_{60}=N_{m} C_{N} C_{E} C_{B} C_{R} C_{S}
$$


in which (N1)60 is the corrected SPT blow count, Nm is the SPT recorded in the boring log, and CNCECBCRCS is the product of correction factors for effective overburden pressure, hammer energy ratio, borehole diameter, rod length, and sample liners, respectively, as described by Idriss and Boulanger [2008]. The correction factors were determined directly from information collected from boring logs, driller logs, geotechnical reports that accompanied the data, and discussions with personnel associated with the site investigations.

Sandy soils below the water table with low FSL are indicated in the cross-section. With the exception of the sand deposit in Boring 8 with a very low N-value, the FSL of these soils was mostly between 0.60 and 1.06. Some thin layers of sand were observed to be unstable and running during the borehole drilling, and they are identified as being potentially liquefiable. The cross-section shows that there are local lenses and layers of liquefiable sands. Hence, liquefaction or cyclic mobility during the Northridge earthquake may have been confined to local layers of sandy soil. The absence of direct evidence of liquefaction (e.g., sand boils and lateral spreading) in this area is consistent with the local nature of the liquefiable deposits. Reductions in shear modulus caused by elevated pore pressures in the loose sands during the earthquake may have contributed to local amplification of ground motion. Shear modulus reduction in sand layers within the upper $12.5 \mathrm{~m}$ of the soil column would increase the surface ground motions in a manner similar to that shown by the analyses of Boore, et al. [2003].

In summary, there is compelling evidence for seismic hazard in the La Cienega area associated with elevated levels of strong ground motion. The location of highest 
hazard, as evinced by local pipeline and bridge damage, appears to be located in a zone of previous swamps and streams that defines a low-lying topographic basin just north of Ballona Creek in the vicinity of La Cienega Blvd. Soft sediments associated with organic silts and clays remnant of previous marsh and streams, as well as liquefiable sands, could have influenced strong motion during the Northridge earthquake, and constitute a hazard for both transient and permanent ground deformation during a future earthquake. 


\section{CHAPTER 7}

\section{MODELING PIPELINE RESPONSE TRANSIENT GROUND DEFORMATION}

PGVs predicted by the ShakeOut Scenario and measured during the Northridge earthquake are at comparable levels in the West Valley and Van Norman Complex areas shown in Figure 2. Moreover, trunk lines repaired after the Northridge earthquake in these areas remain vulnerable near and at locations of previous repair work. Given the similarity of ShakeOut and Northridge strong motions and the elevated potential for damage to the same pipelines that were damaged during the Northridge earthquake, it was decided to use the Northridge earthquake effects in these areas as a baseline for predicting damage. A pattern of trunk line damage from the ShakeOut scenario similar to that caused by the Northridge earthquake was therefore assumed in the West Valley and Van Norman Complex areas.

Because of the seismic hazard described above for the La Cienega area, it was assumed that one of the LADWP trunk lines in this area would be damaged and leaking during the ShakeOut scenario. Moreover, damage at this location during the Northridge earthquake was used to guide the modeling process for damage to distribution pipelines caused by the ShakeOut scenario earthquake.

Repair rates in the distribution system were modeled as being the larger of either: 1) RRs estimated on the basis of ShakeOut PGVs as described above, or 2) RRs consistent with those caused by the Northridge earthquake. Option 1 resulted in larger RRs for the West Valley and Van Norman Complex areas and was therefore used for these areas, and Option 2 was used for the La Cienega area. 


\section{CHAPTER 8}

\section{PIPELINE DAMAGE FROM PERMANENT GROUND DEFORMATION}

The places where LADWP trunk lines intersect liquefaction hazards identified in the ShakeOut scenario earthquake were located by GIS to find where they are at highest risk of disruption from liquefaction-induced ground deformation. Damage to the trunk line system was then evaluated using the decision process illustrated in Figure 6.

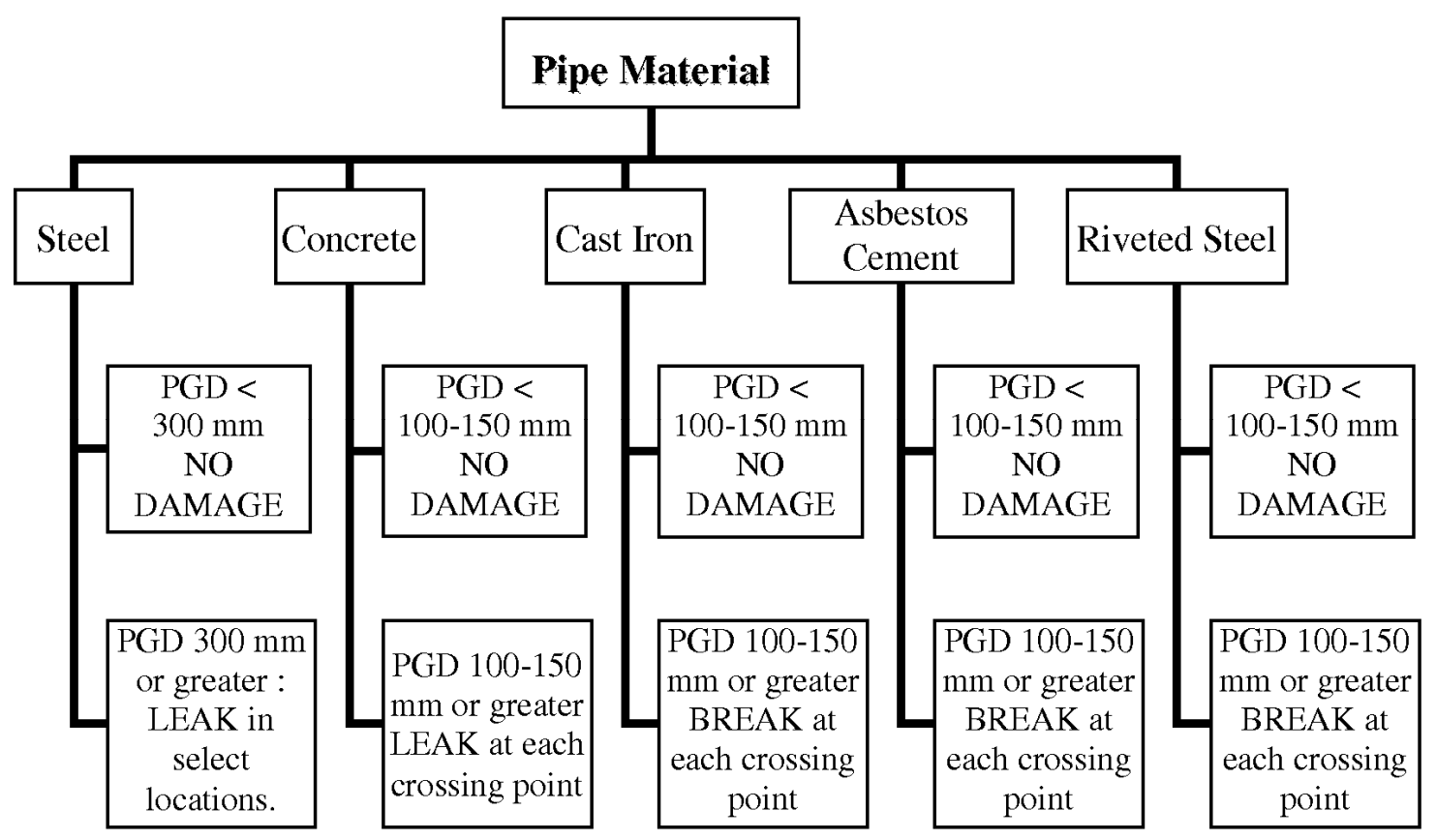

Figure 6. Flow charts for estimating pipeline damage at PGD locations.

Damage to the most fragile pipelines, composed of cast iron and asbestos cement, was modeled as a pipeline break where the pipelines cross zones of predicted ground movement of $100-150 \mathrm{~mm}$ or greater. Damage to jointed concrete and riveted steel pipelines was modeled as a pipeline leak where the pipelines cross zones of predicted ground movement of $100-150 \mathrm{~mm}$ or greater. Damage to welded steel pipelines, 
typically constructed with welded slip joints, was modeled as leakage at select locations where the pipelines cross zones with greater than $300 \mathrm{~mm}$ of ground movement. A special algorithm described by Shi [2006] and Bonneau [2008] was used to predict leakage on the basis of pipeline type, likely modes of pipeline damage, and diameter. 


\section{CHAPTER 9}

\section{SHAKEOUT SCENARIO PIPELINE DAMAGE AND SYSTEM SERVICEABILITY}

Hydraulic network analyses were performed with GIRAFFE using damage states associated with PGD and TGD as described above. Damage caused by PGD was modeled at specific locations in the system where LADWP pipelines cross PGD zones (see Figure 2) in accordance with the decision process depicted in Figure 6. Damage to pipelines and facilities, such as tanks, caused by TGD was modeled by means of the fragility relationships described previously. Such damage cannot be located explicitly, but is distributed throughout the system as described by Shi [2006] and Bonneau [2008] assuming that the generation of damage is consistent with a Poisson's process. Monte Carlo simulations were run for TGD-induced damage using a special algorithm that evaluates the mean and standard deviation of the system serviceability index (SSI), defined as the ratio of water available at all system nodes after the earthquake to water available before the earthquake. The SSI mean and standard deviation are computed after each successive run until the standard deviation converges to within 0.02 of the mean.

All simulations were run for summer daily water demands. Such water usage was chosen to reflect post-earthquake conditions where service line leakage and damage to the interior piping of buildings and residential structures would draw more water from the system. Maximum demand typically occurs during the summer, and is somewhat higher than the demand that typically would be expected at the time of the ShakeOut emergency exercises. 
Figure 7 presents a bar chart of the estimated pipeline repairs throughout the entire system caused by the ShakeOut scenario earthquake. The numbers of pipeline breaks and leaks are shown for the trunk line and distribution system .For this bar chart, trunk and distribution pipelines are those with nominal diameters $\geq 600 \mathrm{~mm}$ and $<600 \mathrm{~mm}$, respectively. The percentages of breaks and leaks simulated by GIRAFFE are set by the user. Breaks account for $5 \%$ of the damage and leaks account for the remainder. In this case, the percentages reflect those observed in the LADWP system after the Northridge earthquake.

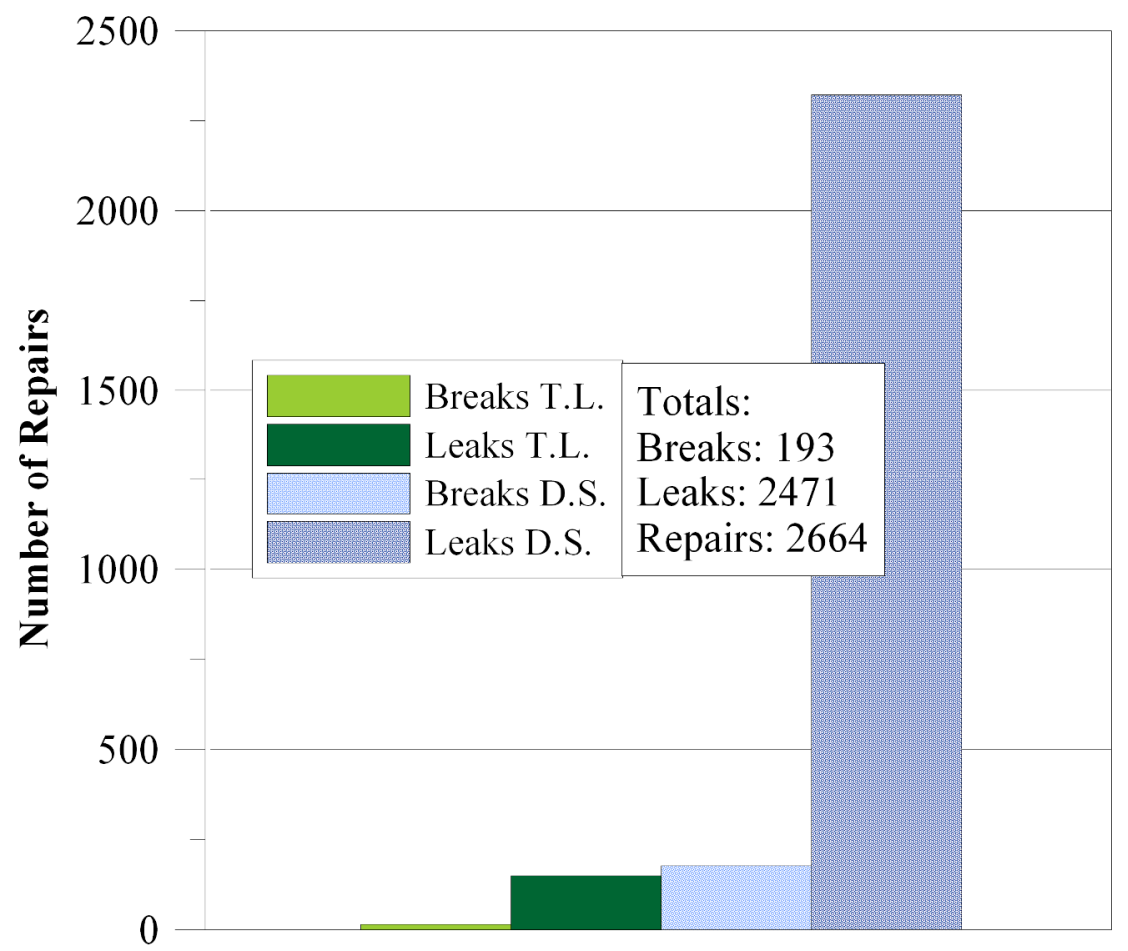

Figure 7. Bar chart of pipeline repairs caused by ShakeOut scenario earthquake

Such information helps to understand the potential scale of the damage and provides emergency planners with guidance about the number of personnel required for system restoration and stockpiling of equipment for rapid repair. There are approximately 
2,700 locations of pipeline damage predicted for the ShakeOut scenario earthquake. This compares with approximately 1,100 repairs after the 1994 Northridge earthquake. The higher number of repairs is driven primarily by the large PGVs associated with the ShakeOut ground motions over a larger area.

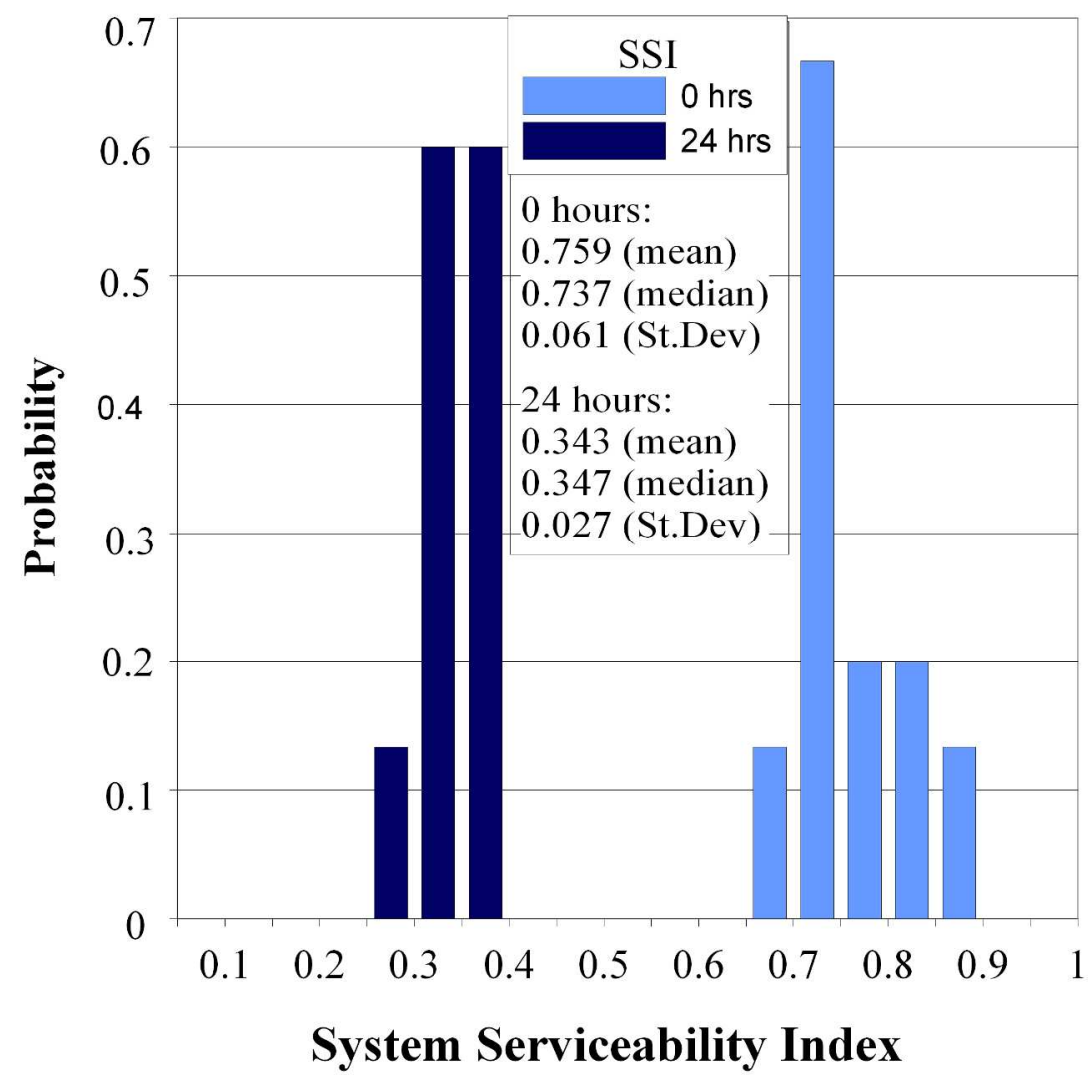

Figure 8 . Histogram of system serviceability immediately following and 24 hours after the ShakeOut scenario earthquake

Figure 8 presents the SSI statistics for 0 and $24 \mathrm{hrs}$ after the earthquake. Histograms are shown in which the number of Monte Carlo simulations resulting in a particular SSI is divided by the total number of simulations to provide an approximate probability index. The histograms of "probability" allow one to compare performance 
outcomes immediately after the earthquake and $24 \mathrm{hrs}$ later. At $0 \mathrm{hrs}$ the SSI has a mean of $76 \%$, which decreases to a mean of $34 \%$ after 24 hrs. The simulations show that within one day approximately $66 \%$ of the system on average is unable to provide water at reliable levels of pressure and flow. As shown by the histograms there are some possible outcomes in which SSI drops as low as $25 \%$. An effective use of the GIRAFFE simulations is to examine in detail the reasons for the lowest levels of performance. Such assessments reveal important vulnerabilities and suggest retrofitting and improvements in emergency response to boost system resilience.

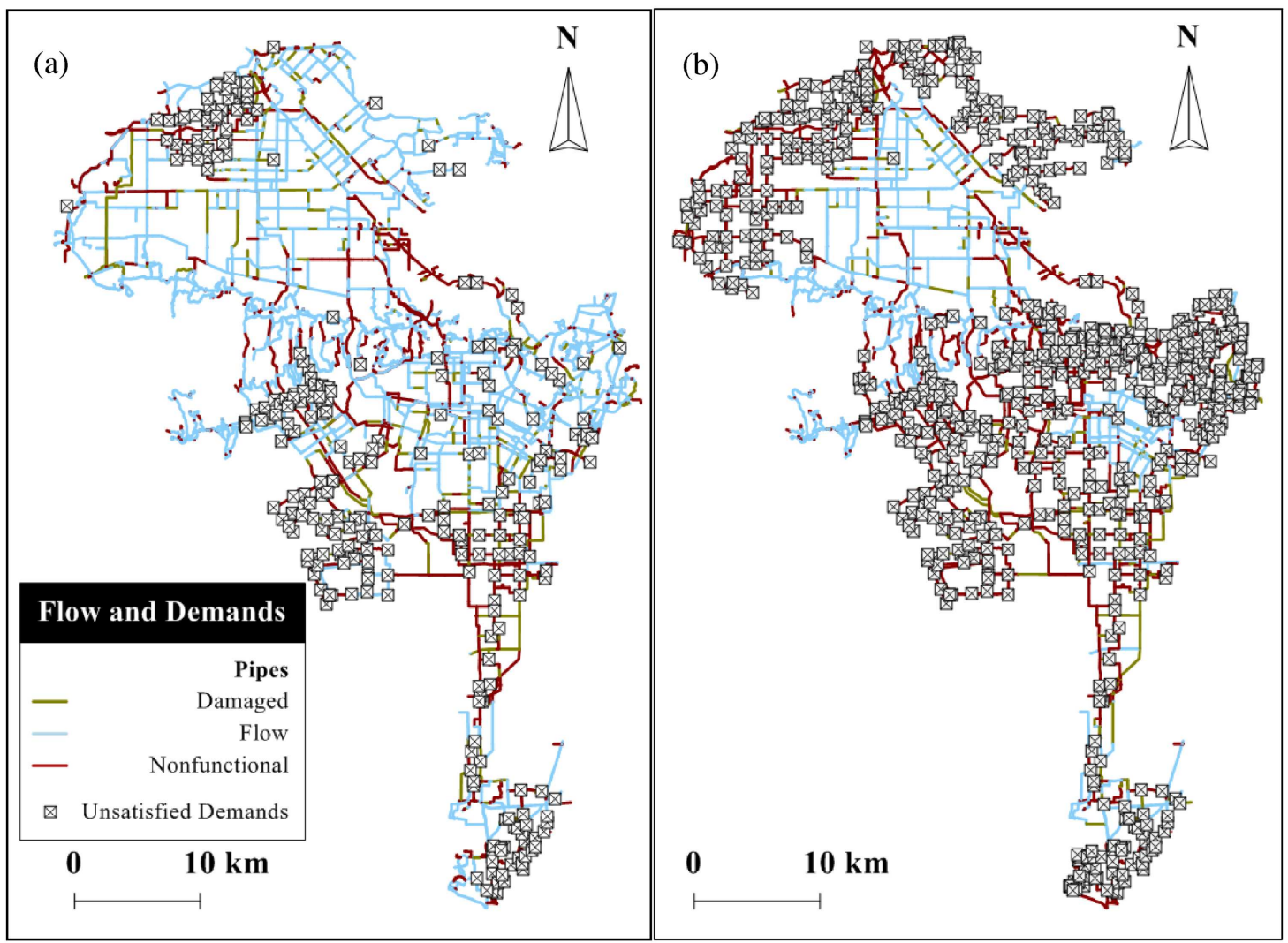

Figure 9. System flow state and unsatisfied demands for: (a) 0 and (b) 24 hours after the ShakeOut scenario earthquake. 
The deterioration in water supply performance is generated by losses from leaking pipelines that draw down tanks and reservoirs, causing some sections of the system to lose all local sources of water. Following such a large event, it will take some time to isolate and repair leaking pipelines. A period of $24 \mathrm{hrs}$ was chosen in consultation with LADWP personnel as a representative interval for showing time-dependent losses before significant repair and restoration can be initiated. In addition, the LADWP has 35 water supply connections with MWD. In this analysis, the MWD transmission system is assumed to be sufficiently damaged that supply water cannot be provided to LADWP within the simulation time frame.

Figure 9 shows the flow conditions in the trunk line system at 0 and 24 hrs after the earthquake for a single network analysis representing the median results of the Monte Carlo simulations. This figure provides information about the spatial distribution of flows and the way they diminish with time. The decrease in pipelines with reliable water flow and the increase in unsatisfied demand nodes are clearly shown by comparison of the 0 and $24 \mathrm{hr}$ condition. 
There are 1,052 demand nodes that are geographically distributed throughout the system model. The SSI can be determined for the entire system, or a local serviceability index (SI) can be determined through GIS as the ratio of flow at demand nodes in specific locations before and after the earthquake.

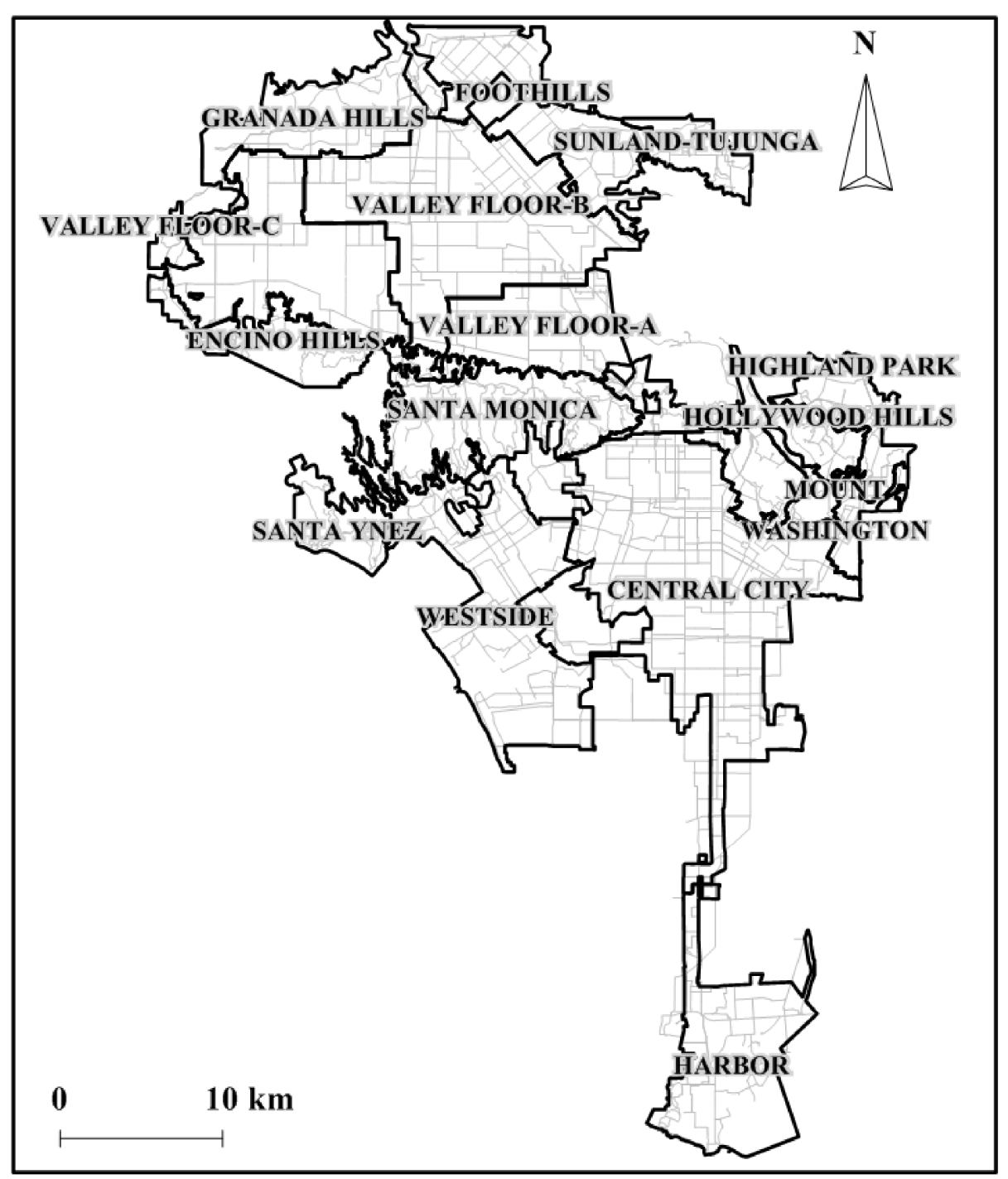

Figure 10. Location of LADWP water service areas 


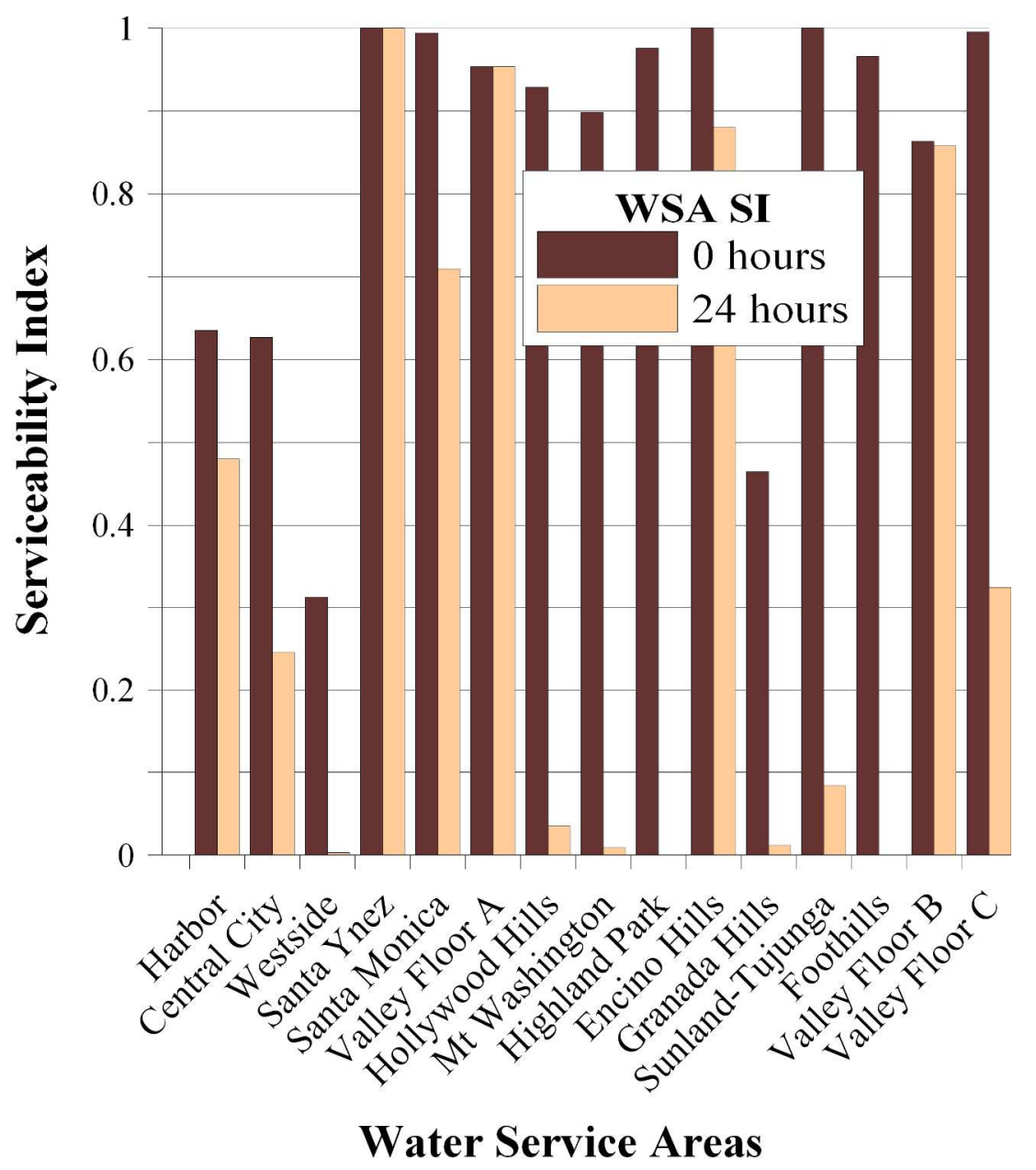

Figure 11. Bar chart of LADWP water service areas serviceability index (SI)

The system response was evaluated for the 15 water service areas shown in Figure 10. Water service areas are geographic groupings of pipelines, pumps, valves, tanks, reservoirs, and demands that are evaluated individually by LADWP. From north to south the water service areas are: Granada Hills (GH), Foothill (FH), Sunland-Tujunga (ST), Valley Floor A, B and C (VF A, VF B, VF C), Encino Hills (EH), Santa Monica (SM), Hollywood Hills (HH), Mount Washington (MW), Highland Park (HP), Santa Ynez (SY), Westside (WS), Central City (CC), and Harbor (H). The WS, CC, HP, and MW service areas are located in the zones of highest population density 
[Bonneau, 2008]. By showing the results for the 15 water service areas, one is able to understand the spatial variability of system performance as expressed in terms of SI, and evaluate water supply response in areas of particular concern, such as those with highest population density.

A bar chart for the SIs of the service areas is presented in Figure 11 for 0 and 24 hrs after the earthquake. The plot represents the median results of the Monte Carlo simulations. In this display the local losses in serviceability can be assessed with a relatively high degree of geographic detail. For example, the SIs at 24 hrs after the earthquake for three of the most densely populated zones in the WS, HP, and MW service areas show SIs of almost 0\%, well below the mean SSI of 34\%. The reasons for these low pockets of SI can be assessed by looking into the details of the hydraulic network analyses at these specific locations. In the WS, HP, and MW areas there are locations of PGD caused by soil liquefaction that contribute to pipeline damage and diminished flow. 


\section{CHAPTER 11 \\ EMERGENCY USE OF RESERVOIRS}

LADWP is presently undertaking an extensive capital improvement program to meet the requirements of the U.S. Environmental Protection Agency and California State Department of Health Services requirements with respect to surface water treatment and disinfection byproducts. Significant water system changes are necessary to meet the requirements. System changes include the removal of Encino, Hollywood, and Lower Stone Canyon Reservoirs from normal operating service, which places a much greater importance on the Los Angeles Reservoir for potable water supply. There is still the ability, however, to reconnect the Encino, Hollywood and Lower Stone Canyon Reservoirs for emergency use.

Figure 12 shows the locations of the Los Angeles, Encino, Lower Stone Canyon, and Hollywood Reservoirs, as well as the approximate volume of water storage at each one. Removing the Encino, Lower Stone Canyon, and Hollywood Reservoirs takes away up to 30 million $\mathrm{m} 3$ of water from immediate use.

\footnotetext{
Although in-city storage capacity is being reduced, new trunk lines are being constructed that provide greater redundancy and flexibility. It is important to understand how the ability of the Los Angeles water system to withstand seismic hazards is affected as the water quality standards and new trunk line installations that are being implemented. The system changes necessary to meet water quality standards raise questions concerning how the system may perform in future earthquake scenarios similar to or greater than what Los Angeles experienced in the 1971 San Fernando and 1994 Northridge earthquakes.
} 


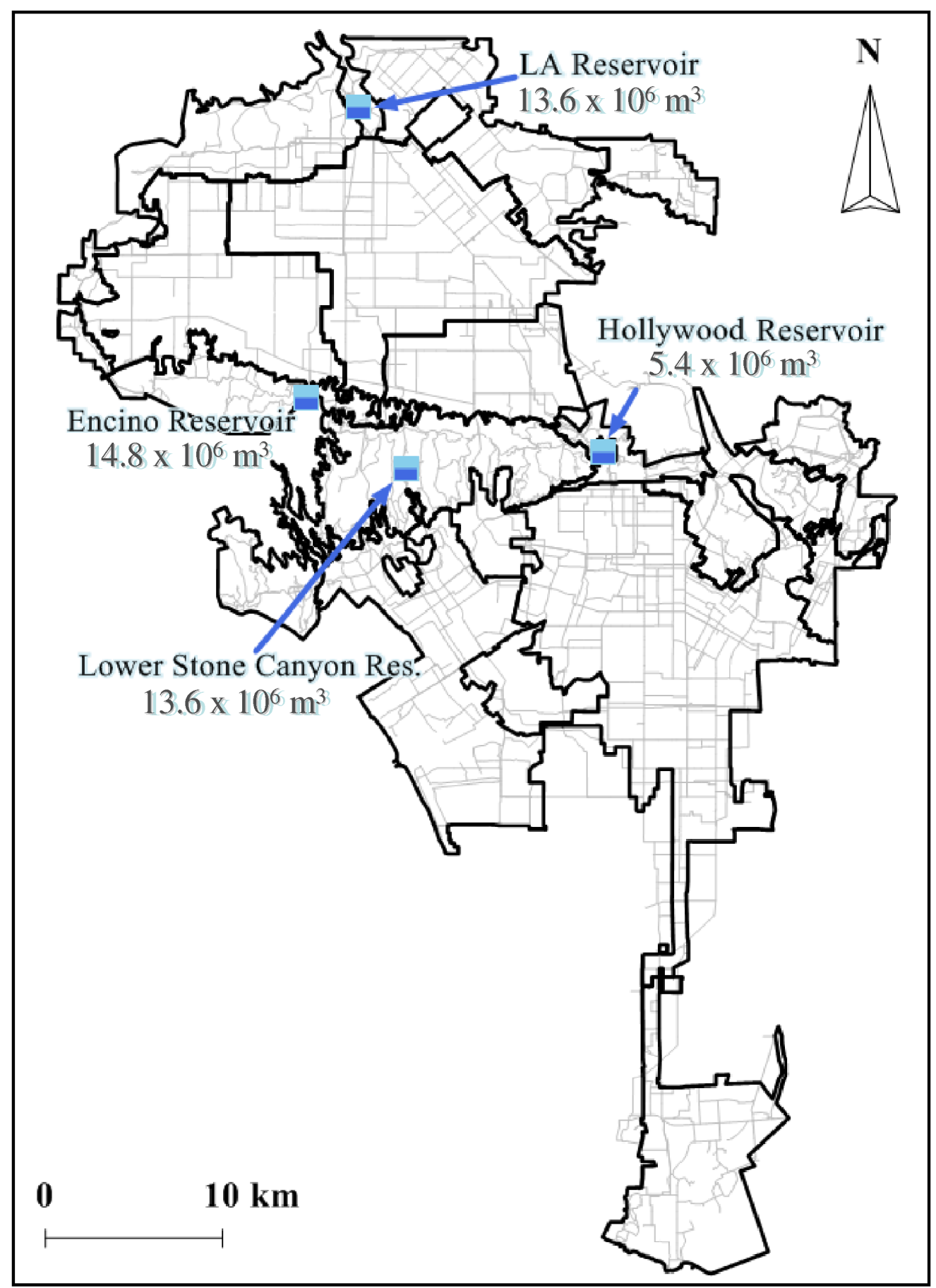

Figure 12. Locations of LA, Encino, Lower Stone Canyon and Hollywood reservoirs 
Figure 13 provides a graphical display of the LAWDP system response to the ShakeOut earthquake scenario with and without the disconnected reservoirs. The SSI statistics for 24 hrs after the earthquake are summarized in the histogram. The number of Monte Carlo simulations, which contribute to a particular SSI, was divided by the total number of simulations to provide an approximate probability index. The histograms of "probability" allow one to compare performance outcomes when the Encino, Lower Stone Canyon, and Hollywood Reservoirs are closed and open. The mean SSI increases by about $8 \%$ when the reservoirs are open as opposed to closed. The shift in the probability distributions can be seen clearly in the figure.

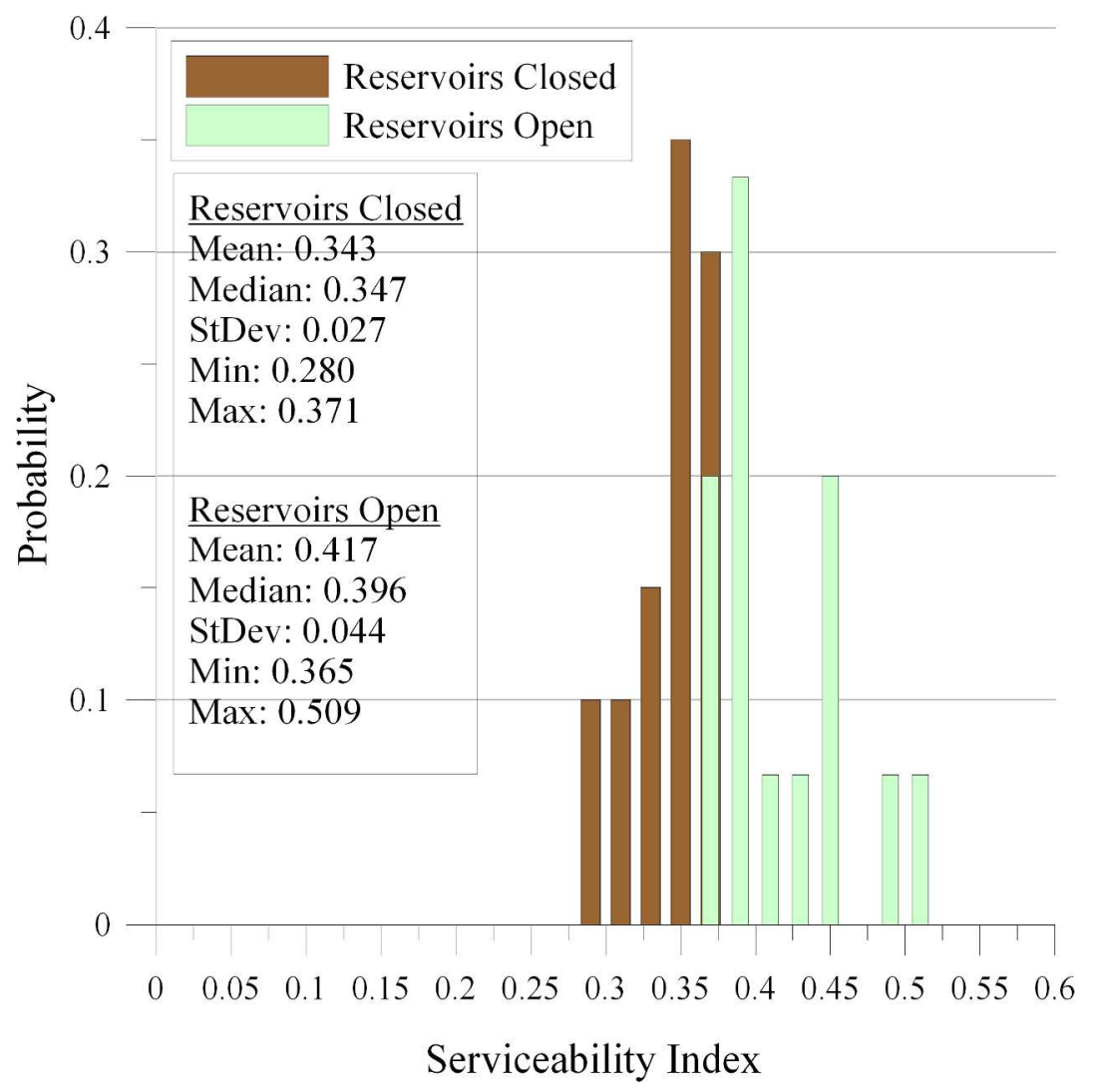

Figure 13. SSI at 24 hours for ShakeOut scenario earthquake, using summer demands with Encino, Lower Stone Canyon and Hollywood reservoirs open and closed. 
Figure 14 provides a similar display in which service area SIs associated with the most populated areas of Los Angeles are represented. These areas include water service areas, WS, CC, HP, and MW, which are geographically close to the Encino, Lower Stone Canyon, and Hollywood Hills Reservoirs. Because of the locally high populations, these areas of Los Angeles are likely to have the greatest need for water to fight post-earthquake fires.

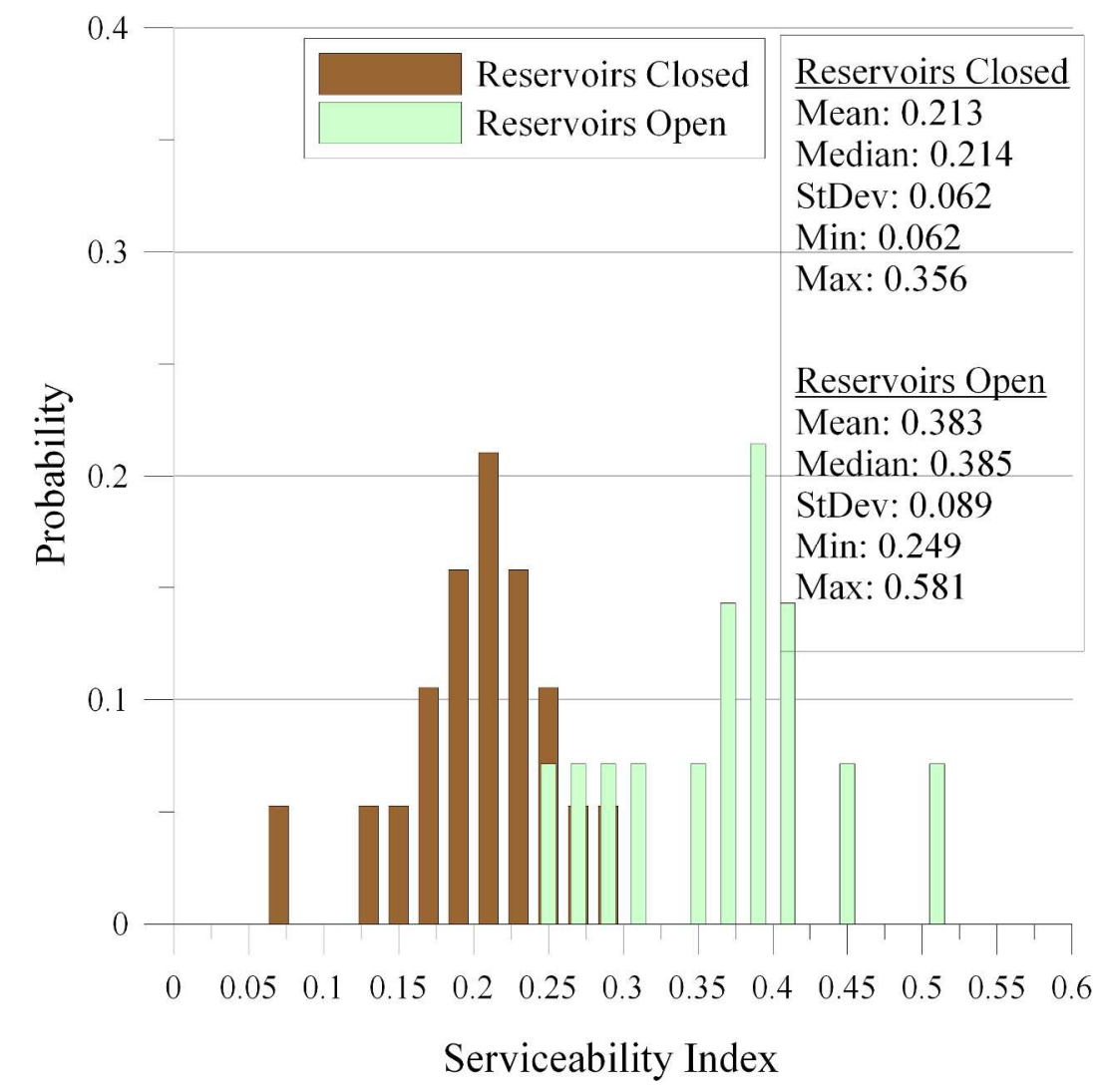

Figure 14. SI for WS, CC, HP, and MW water service areas at 24 hours after the ShakeOut scenario earthquake, using summer demands with Encino, Lower Stone Canyon and Hollywood reservoirs open and closed.

The probability distributions for the most populated areas are substantially different from those for the entire system. The mean SI decreases from 0.38 with reservoirs 
open to 0.21 with reservoirs closed. Not only does the mean SI increase by nearly $50 \%$ with reservoirs open, but the variance in outcomes decreases so that worst case possibilities are less likely. Perhaps the most important finding is that the worst case outcomes with reservoirs closed vary from 0.05 to 0.15 . Such low levels of water service would expose the most populated areas of Los Angeles to exceptionally high risk.

With reservoirs open the probability distributions shift markedly to the right such that the worst case scenarios have SIs higher than the mean SI for reservoirs off. In some cases, water is available at nearly $50 \%$ of the demand nodes after 24 hrs. The results show that opening the reservoirs immediately after a serious earthquake improves serviceability so significantly that it is a plausible strategy for optimal emergency response, even though such action will require tap water safety notices to be issued for the entire system.

These simulations illustrate how complex system decisions involving long-tern water quality standards and short-term emergency response measures can be supported by advanced systems modeling. Work, such as this, that links emergency response with public health decisions provides a good example of how system modeling provides the basis for decisions about geotechnical effects on a regional scale and the complex performance of critical lifeline networks. 


\section{CHAPTER 12}

\section{CONCLUSIONS}

This paper presents the principal results for a simulation of the LADWP water transmission and distribution systems to a 7.8 MW earthquake on the southern San Andreas Fault. The simulation was performed as part of the 2008 ShakeOut earthquake preparedness drill, which was the largest exercise of its kind in US history. The simulation was performed with a decision support system and associated software developed through collaboration among university researchers and LADWP. The system is generic, and the architecture of its computer programs is adaptable to any water supply. The system works in conjunction with an easily accessible hydraulic network model, EPANET, which is available on-line from the U.S. Environmental Protection Agency [EPA, 2007] as well as a special program for damaged network flow modeling, known as Graphical Iterative Response Analysis for Flow Following Earthquakes (GIRAFFE).

The simulation covered all 11,691 km of water trunk and distribution pipelines and related facilities (e.g., tanks, reservoirs, pressure regulation stations, etc.) in the LADWP system, plus the performance of the Los Angeles Aqueducts. The effects of seismic ground waves and of permanent ground deformation associated with fault rupture, liquefaction, and landslides, were modeled.

Performance is quantified by means of a system serviceability index (SSI) and local serviceability index (SI) defined as the ratio of water flow after to water flow before the earthquake on both a system-wide and local level, respectively. The simulations show serious deterioration in the ability to deliver water $24 \mathrm{hrs}$ after the earthquake, 
which is generated by losses from leaking pipelines that draw down tanks and reservoirs. The mean SSI declines from 76 to $34 \%$ over $24 \mathrm{hrs,} \mathrm{which} \mathrm{means} \mathrm{that} 66 \%$ of the normal water demand cannot be met one day after the main shock. The simulation shows nearly 2,700 locations of pipeline repair. Such damage requires careful planning to mobilize a work force of sufficient size for timely recovery and to acquire the parts and equipment for emergency repairs. Serviceability indices are summarized for 15 water service areas to show the spatial variability of system performance and evaluate water supply response in areas of particular concern, such as those with highest population density. Three locations of high population density show complete loss of service, thereby identifying locations of locally high vulnerability and potentially severe consequences.

The LADWP system was modeled with and without several key reservoirs, which have been removed from normal operating service to meet water quality standards. The results show that opening the disconnected reservoirs immediately after a serious earthquake improves serviceability so significantly that it is a plausible strategy for optimal emergency response, even though such action will require tap water safety notices to be issued for the entire system. Work, such as this, that links emergency response with public health decisions provides a good example of how system modeling supports decisions about geotechnical effects on a regional scale and the complex performance of critical lifeline networks. 


\section{REFERENCES}

ASTM [1999] "Standard test method for penetration test and split-barrel sampling of soils," Annual Book of ASTM Standards, American Society for Testing and Materials, D 1586-99, March 1999.

Bonneau, A. L. [2008] "Water supply performance during earthquakes and extreme events.” Ph D. thesis, School Civil and Environmental Engineering, Cornell University, Ithaca, New York.

Boore, D.M., Gibbs, J.F, Joyner, W.B, Tinsley, J.C., and Ponti, D.J. [2003] "Estimated ground motion from the 1994 Northridge, California, earthquake at the site of Interstate 10 and La Cienega Boulevard Bridge collapse, West Los Angeles, California," Bulletin of the Seismological Society of America, 93(93), 27372751.

California State Water Resources Control Board, CA.GOV [2009] Geotracker, retrieved January 2009 <http://geotracker.swrcb.ca.gov/>

Cox, D. and Pierce, I. [2008] "Results are in: great Southern California ShakeOut successful, sets U.S. record!," USGS Newsroom. 19 December 2008. < http://www.usgs.gov/newsroom/article.asp?ID=2098>.

Davis, C.A. [2009a] "Los Angeles Water Supply Impacts from M7.8 San Andreas Fault Earthquake Scenario,” International Water Association 8th International Symposium on Water Supply Technology, Kobe, Japan, paper 20039.

Davis, C.A. [2009b] "Scenario Response and Restoration of Los Angeles Water system to a Magnitude 7.8 san Andreas Fault Earthquake," Proc. 7th U.S. Conf. on Lifeline Earthquake engineering, ASCE, Oakland, June 28 - July 1, paper 232. 
Environmental Protection Agency, EPA [2007]. EPANET. <http://www.epa.gov/nrmrl/wswrd/dw/epanet.html>

Federal Emergency Management Agency, FEMA [2003] HAZUS-MH MR2 Technical Manual. FEMA, Washington, D. C.

Federal Emergency Management Agency, FEMA [2006] Multi Hazard Loss Estimation Methodology Earthquake Model, HAZUS-MH MR3, Technical Manual, Department of Homeland Security Emergency Preparedness and Response Directorate, FEMA Mitigation Division, Washington, District of Columbia <http://www.fema.gov/plan/prevent/hazus/hz_manuals.shtm>

Holzer, T.L., Bennet, M.J., Ponti, D.J., and Tinsley III, J.C. [1999] "Liquefaction and soil failure during 1994 Northridge earthquake", Journal of Geotechnical and Geoenvironmental Engineering, ASCE, 125(6), 438-452.

Idriss, I.M. and Boulanger, R.W. [2008] Soil Liquefaction During Earthquakes, Earthquake Engineering Research Institute, Oakland, California.

Isenberg, J. [1986] "Post-earthquake performance of pipelines at Coalinga," Earthquake Spectra, EERI, 2(4), 729-745.

Jeon, S.-S. and O'Rourke, T.D. [2005] “Northridge earthquake effects on pipelines and residential buildings," Bulletin of the Seismological Society of America, 95(1), 294-318.

Lisle, M.J. De. [1998] "Liquefaction zones in the Beverly Hills 7.5-minute quadrangle, Los Angeles County, California," in Seismic Hazard Zone Report for the Beverly Hills 7.5-Minute Quadrangle, Los Angeles County, California. (Department of Conservation, Division of Mines and Geology, California, 2001), pp. 3-15. 
Makdisi, F.I. and Seed, H. B. [1978] "Simplified procedure for estimating dam and embankment earthquake-induced deformations," Journal of the Geotechnical Engineering Division, ASCE, 104(GT7), 849-867.

Mattison E. and Lloyd, R.C. [1998] "Liquefaction zones in the Hollywood 7.5-minute quadrangle, Los Angeles County, California," in Seismic Hazard Zone Report for the Hollywood 7.5-Minute Quadrangle, Los Angeles County, California. (Department of Conservation, Division of Mines and Geology, California, 2001), pp. 3-15.

O’Rourke, M.J. and So, P. [2000] "Seismic fragility curves for on-grade steel tanks," Earthquake Spectra, Vol. 16, No. 4, 801-815

O’Rourke, T.D. [1998], "An Overview of Geotechnical and Lifeline Earthquake Engineering", in Geotechnical Special Publication No. 75,, Proc. of Geotechnical Earthquake Engineering and Soil Dynamics Conference held in Seattle, Washington, Aug. 1998, Vol 2, ed. P. Dakoulas and M. Yegian (ASCE, Reston, Virginia) pp.1392-1426.

O’Rourke, T.D. and Toprak, S. [1997] "GIS assessment of water supply damage from the Northridge earthquake," in Spatial Analysis in Soil Dynamics and Earthquake Engineering (GSP 67), ed. D. Frost (ASCE, Reston, Virginia), pp. $117-132$.

O’Rourke, T.D., Jezerski, J.M., Olson, N.A., Bonneau, A.L., Palmer, M.C., Stewart, H.E. and O’Rourke, M.J. [2008] “Geotechnics of pipeline system response to earthquakes", Proceedings, Conference of Geotechnical Earthquake Engineering and Soil Dynamics IV (GEESD) Sacramento, California, pp. 138.

Rosrine [2001] ResOlution of Site Response Issues from the Northridge Earthquake, Rosrine, retrieved January 6, 2009 from <http://gees.usc.edu/ROSRINE/> 
Shi, P. [2006] "Seismic response modeling of water supply systems." Ph.D. thesis, school of Civil and Environmental Engineering, Cornell University, Ithaca, NY.

Shi, P., O’Rourke, T.D., and Wang, Y. [2006] "Simulation of earthquake water supply performance." Proceedings, 8th National Conference on Earthquake Engineering, Paper No. 8NCEE-001295, EERI, Oakland, California.

Tokimatsu, K. and Seed, H.B. [1987] "Evaluation of settlements in sands due to earthquake shaking," Journal of the Geotechnical Engineering Division, ASCE, 113(8), $861-878$.

USGS [1896] 1893 - 94 Los Angeles Topographic[map]. 1:62,500. USGS, 1896.

USGS [1925] 1923 - 25 Eastern Part of the Santa Monica Mountains and Adjacent Areas, Los Angeles County, Calif. [map]. 1:24,000. USGS.

USGS [1926] 1923 - 24 Hollywood quadrangle, Los Angeles County, Calif. [map]. 1:24,000. 6 Minute Series. City of Los Angeles, California. USGS, 1926.

USGS [1999a] Seismic Hazard Zone Beverly Hills Quadrangle [map]. 1:24,000. 7.5Minutes Series. State of California: USGS, 1999.

USGS [1999b] Seismic Hazard Zone Hollywood Quadrangle [map]. 1:24,000. 7.5Minutes Series. State of California: USGS, 1999.

USGS [2008a] The ShakeOut Scenario. USGS Open File Report 2008-1150, CGS Preliminary Report 25. U.S. Geological Survey, California Geological Survey. retrieved January 2009 < http://pubs.usgs.gov/of/2008/1150/>.

USGS [2008b] ShakeMap for ShakeOut Scenario. Earthquake Center ShakeMap, Southern California. U.S. Geological Survey, retrieved November 2008. <http://earthquake.usgs.gov/eqcenter/shakemap/sc/shake/ShakeOut2_full_se/>. 
USGS [2008c] Northridge Earthquake. Earthquake Center ShakeMap, Southern California. U.S. Geological Survey, retrieved May 2009. <http://www.cisn.org/shakemap/sc/shake/Northridge/products.html>.

Wang, Y. [2006] "Seismic performance evaluation of water supply systems." Ph.D. thesis, School of Civil and Environmental Engineering, Cornell University, Ithaca, New York.

Wang, Y. and O'Rourke, T.D. [2007] "Characterizations of seismic risk in Los Angeles water supply system," Proceedings, 5th China-Japan-US Trilateral Symposium on Lifeline Earthquake Engineering, Haikou, China, pp. 391-399.

Wilson, R.C. and Keefer, D.K. [1985] "Predicting areal limits of earthquake induced lansliding," in Evaluating Earthquake Hazards in the Los Angeles Region: U.S. Geological Survey Professional Paper, ed. J.I. Ziony, pp. 317-493.

Yashinski, M. [1995a] "Bridges and roadways," Northridge earthquake, Lifeline performance and post-earthquake response, ed. A.J. Schiff (American Society of Civil Engineers, New York, NY), pp. 158-209.

Yashinski, M. [1995b] "Damages to bridges and highways from the Northridge Earthquake," The Northridge California, Earthquake of 17 January 1994, ed. M.C. Woods and W.Ray Seiple (California Department of Conservation, Division of Mines and Geology, Sacramento California), pp. 163-185.

Youd, T.L. and Perkins, D.M. [1987] "Mapping of liquefaction severity index," Journal of Geotechnical Engineering, ASCE, 113(11), 1374-1392. 